\title{
A Review of Load Sharing Principle for Thoracolumbar Fractures
}

\author{
Huilin Yang*, Jun Pan and Zhonglai Qian
}

Department of Orthopedics of 1st Affiliated Hospital, Soochow University, Suzhou, Jiangsu, China

\begin{abstract}
Summary of background datas: The management for thoracolumbar fractures remains challenging. It is still controversial which surgical option and approach can correct the deformity, induce neurological recovery, allow patients early mobilization and return to work with minimal risk of complication. The load sharing classification was proposed to describe the thoracolumbar fracture and guide the surgical approach and widely used.
\end{abstract}

Objectives: To review the related studies reporting the load sharing classification for the management of thoracolumbar fractures, discusses the generation, biomechanics, clinical application and advancement of load sharing classification.

Material and Methods: PubMed was used to search for articles published from January 1992 to January 2013 using keywords (thoracolumbar fracture and load sharing). References were checked to identify additional studies.

Results: There were 19 original articles that ultimately constituted the basis for the review. 16 prospective or retrospective studies reporting clinical results using load sharing classification to treat the thoracolumbar fracture were listed. The sample size was relatively small and it was difficult to compare the results among different studies without the same outcome measures or length of follow-up periods.

Conclusion: The optimal surgical method to reduce the postoperative complications and maintain the favorable long-term result for thoracolumbar fractures, all of these are still the challenges of the spine surgery. The load-sharing theory and the load-sharing classification have made contribution to solve the above problems and laid the theoretical basis and provided the clinical guideline meanwhile.

Keywords: Thoracolumbar fractures; Load sharing

\section{Introduction}

Spinal fracture mostly occurs in the thoracolumbar region, burst fracture composing approximately $10 \%-20 \%$ of such injuries [1-3]. The thoracolumbar burst fracture is usually characterized by most spine surgeons as an unstable fracture and treated with various surgical options. However, it is controversial how these fractures should be approached and stabilized anteriorly, posteriorly or combined anteropostierorly [3-5]. Therefore, there are several classification systems available to help surgeon know the association between fracture pattern and therapeutic options. In 1994 McCormack et al. [6] developed the load sharing classification which used a scoring system to describe the spinal fracture and imply the surgical approach. From then on, the classification has been the subject of debate and study for a long time.

\section{Generation of Load Sharing Principle}

With the invention of pedicle screws, posterior pedicle fixation became a popular way to treat thoracolumbar fracture. However, McLain et al. [7,8] found the clinical results frustrating due to the high ratio of early fixation failure and correction loss at follow-up. Single posterior approach could not solve all thoracolumbar fracture. Therefore, the question as to which approach should be performed to reduce the complications above became a challenge. In 1994, McCormack et al. [6] proposed the load sharing theory based on the results of 28 cases thoracolumbar fractures treated with posterior pedicle screws fixation. According to the principle, failure to support the anterior spinal column after posterior instrumentation with pedicle screws led failure of implants or loss of correction. The classification system contains three separate factors of fractured vertebra to quantify the combination of the vertebral body: the amount of vertebral body combination, apposition of the fracture fragments at the fracture site, and the amount of correction of kyphotic deformity. Each of the 3 factors is awarded 1, 2, and 3 points (mild, moderate, and severe) to describe the severity.
The total point score of every fracture is accumulated from a minimum total of 3 points to a maximum total of 9 points. According to the scoring system, fractures with totaling $\leq 6$ points can be successfully repaired by posterior approach with pedicle screw implants. Severely comminuted fractures scoring to 7 or more points must be repaired by anterior approach with vertebrectomy and strut grafting.

\section{Biomechanics of Load Sharing Classification}

The concept of three-column of Denis [9] divided vertebra into three parts: 1. anterior column consisting of anterior longitudinal ligament and anterior half of vertebral body and annulus fibrosus, 2. middle column consisting of posterior longitudinal ligament and posterior half of vertebral body and annulus fibrosus, finally the rest structures classified as posterior column. The anterior and middle column carry about $80-90 \%$ of the load and the posterior column carries the rest of $10-20 \%$ in the normal upright position [10]. When the burst fracture occurs, anterior column is compressed into a wedge by vertical violence with or without flexion violence, the posterior vertebral wall of middle column is broken and intruded into canal. Thus, the load sharing balance of three column is broke down due to both anterior and middle column are involved. Most of load will be distributed on the pedicle fixation system and posterior column and lead the implants failure without sufficient support on the anterior and middle column after posterior correction.

*Corresponding author: Huilin Yang, Department of Orthopedics of 1st Affiliated Hospital, Soochow University, Suzhou, Jiangsu 215007, China, Tel: 86-0512-67780101; Fax: 86-0512-6778-1165; E-mail: 55982162@qq.com

Received September 13, 2013; Accepted September 28, 2013; Published September 30, 2013

Citation: Yang H, Pan J, Qian Z (2013) A Review of Load Sharing Principle for Thoracolumbar Fractures. J Spine 2: 142. doi:10.4172/2165-7939.1000142

Copyright: $\odot 2013$ Yang H, et al. This is an open-access article distributed under the terms of the Creative Commons Attribution License, which permits unrestricted use, distribution, and reproduction in any medium, provided the original author and source are credited. 
Biedermann [11] reported that $80-90 \%$ of load still distributed on the anterior-middle column after it was rebuilded, the fixation system carried a small amount of load and hardly resulted in implants failure. Rohlmann et al. [12] gained the similar conclusion above in vitro study. Wang et al. [13] made bovine L1 burst fracture model by axial compressive impact with different energy and took radiograph films and CT of the experimental spine after trauma to value the load sharing score, respectively. Measured under flexion-extension, right/left lateral bending, and right/left axial rotation, the results showed significant positive correlation between load sharing score and spinal instability. The authors concluded that load sharing score was helpful in evaluating the instability of thoracolumbar fractures in an in vitro biomechanical validation.

\section{Clinical Application of Load Sharing Classification}

The load sharing classification has been accepted by most spine surgeons and was widely used to guide the treatment for thoracolumbar fracture due to its excellent reliability. Dai and Jin [14] showed high levels of agreement when the Load Sharing Classification was used to assess thoracolumbar burst fractures. Elzinga et al. [15] results were lower levels than Dai's, but the inter- and intraobserver reliability of the Load Sharing Classification of Spinal fractures could still be rated as fair.

Parker et al. [16] reported successful instrumentation of 46 thoracolumbar fracture by using load sharing classification to determine the approach. 30 patients were treated with pedicle screw system using a posterior approach with the load sharing score $\leq 6 \mathrm{pts}$, 16 patients with the score $>6$ pts were treated surgically using an anterior approach with the Kaneda device. Finally 45 cases reached anatomic healing with prospective application of load sharing classification for surgical approach selection. The authors concluded that the load shading classification was the most successful way to predict clinically successful short-segment thoracolumbar spinal fracture repair. According to the load sharing classification and the Gertzbein classification where three mechanisms of injury were identified: Type A, compressive force; Type $\mathrm{B}$, tensile force; and Type C, axial torque, Aligizakis et al. [17] treated 30 consecutive patients including 21 patients with posterior short segment pedicle screw implant, 3 patients with anterior decompression with strut grafting and application of the Kaneda device and 6 patients treated with short posterior instrumentation and an anterior strut graft. No pseudarthrosis and no implant failures were recorded at 24-50 months follow-up. As it was accepted by most spine surgeons, the load sharing classification acted as a inclusion or exclusion criteria in the study. In the prospective randomized study which was designed to evaluate the results of anterior reconstruction with structural grafting verus titanium mesh cage in the treatment of thoracolumbar burst fractures reported by Dai et al. [18], the inclusion criteria specified participants a loadsharing score of 7 or more. Meanwhile in the prospective randomized study reported by Korovessis et al. [19] to compare the results of the combined anterior-posterior surgery with posterior short segment transpedicular fixation in midlumbar burst fractures, 40 consecutive patients with load sharing score 6 or more were recruited.

Load sharing classification is also a reliable tool for the conservative treatment and prognosis of thoracolumbar spinal fractures. Aligizakis et al. [20] concluded that load sharing scoring could perdict the the functional outcome in conservatively treated patients and the authors suggested patients with a Load Sharing score of 6 or less might be suited for conservative therapy. Meanwhile, Dai et al., [21] reported a retrospective study of 127 patients with an acute thoracolumbar burst fracture treated conservatively and their Load Sharing score ranging from 3 to 9. Finally, the authors claimed that the the long-term results of conservative treatment could be predicted by the Load Sharing Classification (Table 1).

\section{The Advancement of Load Sharing Classification}

Load shading classification was used not only in surgical approach

\begin{tabular}{|c|c|c|c|c|c|}
\hline Authors & Type of study & No. of patients & Follow-up & intervention & Results and conclusions \\
\hline $\begin{array}{l}\text { Parker et al., } \\
\text { [16] }\end{array}$ & Retrospective & 46 patients & 66 months & $\begin{array}{l}\text { Posterior approach: } 30 \text { patients with LSS 3-6 } \\
\text { Anterior approach: } 16 \text { patients with LSS 7-9. }\end{array}$ & $\begin{array}{l}45 \text { of } 46 \text { patients instrumented by the short- } \\
\text { segment technique to proceed to successful } \\
\text { healing in virtual anatomic alignment }\end{array}$ \\
\hline $\begin{array}{l}\text { Aligizakis et al., } \\
{[17]}\end{array}$ & Retrospective & 30 patients & $\begin{array}{l}32 \text { months } \\
\text { (range, } \\
24-50 \\
\text { months) }\end{array}$ & $\begin{array}{l}\text { Posterior approach: } 21 \text { patients with LSS } 3-6 \text { pts } \\
\text { and type A of Gertzbein Classification } \\
\text { Anterior approach: } 3 \text { patients with LSS more than } \\
7 \text { pts and type A } \\
\text { Combined approach: } 6 \text { patients with LSS more } \\
\text { than 7pts and type B or C. }\end{array}$ & $\begin{array}{l}\text { satisfactory } \\
\text { in } 22 \text { of } 30 \text { patients. Five of nine patients } \\
\text { had } \\
\text { neurologic improvement. No pseudarthrosis } \\
\text { and no implant failures. }\end{array}$ \\
\hline Dai et al., [18] & $\begin{array}{l}\text { Prospective } \\
\text { randomized }\end{array}$ & 65 patients & $4-7$ years & $\begin{array}{l}\text { All patients with LSS } 7-9 \text { pts, treated with anterior } \\
\text { decompression and reconstruction supplemented } \\
\text { with instrumentation }\end{array}$ & $\begin{array}{l}\text { All patients achieved solid fusion, with } \\
\text { significant neurologic improvement and no } \\
\text { significant correction loss as defined by loss } \\
\text { of kyphosis correction. }\end{array}$ \\
\hline $\begin{array}{l}\text { Korovessis et } \\
\text { al., [19] }\end{array}$ & $\begin{array}{l}\text { Prospective } \\
\text { randomized }\end{array}$ & $\begin{array}{l}40 \text { patients A3-type/ } \\
\text { AO burst fractures and } \\
\text { LSS up to } 6\end{array}$ & 46 months & $\begin{array}{l}\text { Group A: combined anterior-posterior surgery } \\
\text { Group B: posterior "short-segment" transpedicular } \\
\text { fixation"(SSTF) }\end{array}$ & $\begin{array}{l}\text { SSTF did not significantly maintain } \\
\text { the after surgery achieved correction } \\
\text { of local posttraumatic kyphosis for } \\
\text { operative stabilization of fractures with A3- } \\
\text { type/AO burst fractures and load sharing } \\
\text { score up to } 6 \text {. }\end{array}$ \\
\hline $\begin{array}{l}\text { Aligizakis et al., } \\
{[20]}\end{array}$ & Retrospective & 60 patients & 42 months & non-operatively & $\begin{array}{l}\text { Satisfactory in } 55 \text { of } 60 \text { patients. } \\
\text { Load Sharing scoring is a reliable } \\
\text { and easy-to-use classification for the } \\
\text { conservative treatment and prognosis } \\
\text { of thoracolumbar spinal fractures. }\end{array}$ \\
\hline Dai et al., [21] & Retrospective & $\begin{array}{l}127 \text { patients with LSS } \\
3-9 \text { pts (average } 5.3 \text { pts) }\end{array}$ & $\begin{array}{l}7.2 \\
\text { years }(3-12 \\
\text { years })\end{array}$ & non-operatively & $\begin{array}{l}\text { Significant correlation was found between } \\
\text { the Load Sharing score on admission and } \\
\text { the LKC for local kyphosis angle at final } \\
\text { follow-up }\end{array}$ \\
\hline
\end{tabular}

Table 1: Clinical results of following the load sharing classification. 


\begin{tabular}{|c|c|c|c|c|c|}
\hline Authors & Type of study & No. of patients & Follow-up & Intervention & Results and conclusions \\
\hline Yang et al., [27] & Prospective & $\begin{array}{l}37 \text { patients with load } \\
\text { sharing scores }> \\
\text { or }=6 \text { (including } 23 \\
\text { paitents with } 7-9 \text { pts) }\end{array}$ & 2 years & $\begin{array}{l}\text { three-column reconstruction } \\
\text { through single posterior } \\
\text { (TRSP) approach }\end{array}$ & $\begin{array}{l}\text { No patient experienced worsening of neurologic deficits and } \\
\text { other severe complications at last follow-up. }\end{array}$ \\
\hline Scholl et al., [28] & Prospective & $\begin{array}{l}16 \text { patients with LSS } \\
7-9 \text { pts }\end{array}$ & N/A & $\begin{array}{l}\text { short-segment posterior } \\
\text { instrumentation and fusion }\end{array}$ & $\begin{array}{l}7 \text { patients of all had implants failure such as screws bent or broken. } \\
\text { The authors concluded that the load-sharing classification was not } \\
\text { predictive of posterior instrumentation failure. }\end{array}$ \\
\hline Liu et al., [29] & Prospective & $\begin{array}{l}20 \text { patients(including } \\
9 \text { patients with } 7-8 p t s \\
\text { of LSS) }\end{array}$ & $24.7 \pm 8.0$ months & $\begin{array}{l}\text { monosegmental } \\
\text { pedicle screw } \\
\text { instrumentation (MSPI) }\end{array}$ & $\begin{array}{l}2 \text { patients both with } 8 \text { pts had loss of correction at the final } \\
\text { follow-up, other patients obtained satisfied results. }\end{array}$ \\
\hline
\end{tabular}

Table 2: Clinical results of advancing the load sharing classification.

choice but also in sugical decision-making in guiding the treatment of thoracolumbar burst fractures. Though there was great progress in invasive technique such as thoracoscope [22] for thoracolumbar fractures, anterior approach was great challenge which meant more complications than posterior approach such as increased morbidity, blood loss, risk of pleura injure, more complex anatomy, indirect reduction in sagittal alignment and so on $[23,24]$. With the development of a few new instruments, a new operation method was used to treat the severe thoracolumbar fracture. Ayberk et al., [25] and Sasani and Ozer [26] used a new technique for corpectomy and expandable cage placement combined with laminectomy and shortsegment pedicle screw fixation via single-stage posterior approach to treat 8 and 14 cases of acute thoracic or lumbar burst fractures, respectively. They confirmed consistently that the desired three column stabilization could be obtained through single-stage posterior approach based on the good results in the follow-up. Yang et al. [27] reported that a consecutive series of 37 thoracolumbar fractures with load sharing scores $>$ or $=6$ (including 23 patients with 7-9 pts) managed with the similar technique mentioned above named threecolumn reconstruction through single posterior (TRSP) approach. The authors claimed that TRSP approach could provide enough biomechanical stability and be beneficial for neurologic recovery with less complications, which was advisable to consider as the first choice for the thoracolumbar fractures with load sharing scores more than 6 pts. These studies above seemed to violate the "gold standard" of load sharing classification. But the technique used in the series also achieved the goals including decompressing the neural elements, restoring vertebral body height, correcting angular deformity and stabilizing the columns of the spine as well as anterior approach. The anterior-middle column rebuilded through posterior approach reached the balance of spinal loading, which really meant following the load sharing principle.

However, some scholars also questioned or disagreed with the load sharing classification. Scholl et al., [28] reviewed 16 patients with load sharing scores 7-9 pts treated with short-segment posterior instrumentation and fusion, 7 patients of all had implants failure such as screws bent or broken. The authors concluded that the loadsharing classification was not predictive of posterior instrumentation failure. Some authors [29] put forward the concept of monosegmental transpedicular fixation, which meant patients were instrumented with pedicle screws bilaterally into the fractured level and one adjacent level. A cohort of 20 patients with thoracolumbar burst fractures (including 9 patients with 7-8 pts of load sharing scores) were treated with monosegmental transpedicular fixation plus posterior fusion. 2 patients both with 8 pts had loss of correction at the final followup, other patients obtained satisfied results. The authors concluded monosegmental transpedicular fixation was effective for selected thoracolumbar burst fractures using load sharing scores (Table 2).

\section{Conclusion}

The optimal surgical method to reduce the postoperative complications and maintain the favorable long-term result for thoracolumbar fractures, all of these are still the challenges of the spine surgery. The load-sharing theory and the load-sharing classification have made contribution to solve the above problems and laid the theoretical basis and provided the clinical guideline meanwhile. Although some results questioned, we believe it is the expansion and extension of load- sharing theory. With the development of better biomechanical internal fixation instruments and improved minimally invasive surgical techniques, load sharing scores standard may be changed, the principle of load sharing won't be reversed. And all of these are destined to promote the treatment of thoracolumbar fractures and development of spine surgery.

\section{References}

1. Esses SI, Botsford DJ, Kostuik JP (1990) Evaluation of surgical treatment for burst fractures. Spine (Phila Pa 1976) 15: 667-673.

2. Wood K, Buttermann G, Mehbod A, Garvey T, Jhanjee R, et al. (2003) Operative compared with nonoperative treatment of a thoracolumbar burst fracture without neurological deficit. A prospective, randomized study. J Bone Joint Surg Am 85-85A: 773-81.

3. Müller U, Berlemann U, Sledge J, Schwarzenbach O (1999) Treatment of thoracolumbar burst fractures without neurologic deficit by indirect reduction and posterior instrumentation: bisegmental stabilization with monosegmental fusion. Eur Spine J 8: 284-289.

4. Acosta FL Jr, Buckley JM, Xu Z, Lotz JC, Ames CP (2008) Biomechanical comparison of three fixation techniques for unstable thoracolumbar burst fractures. Laboratory investigation. J Neurosurg Spine 8: 341-346.

5. Langrana NA, Harten RD RD, Lin DC, Reiter MF, Lee CK (2002) Acute thoracolumbar burst fractures: a new view of loading mechanisms. Spine (Phila Pa 1976) 27: 498-508

6. McCormack T, Karaikovic E, Gaines RW (1994) The load sharing classification of spine fractures. Spine (Phila Pa 1976) 19: 1741-1744.

7. McLain RF, Burkus JK, Benson DR (2001) Segmental instrumentation for thoracic and thoracolumbar fractures: prospective analysis of construct survival and five-year follow-up. Spine J 1: 310-323.

8. McLain RF, Sparling E, Benson DR (1993) Early failure of short-segment pedicle instrumentation for thoracolumbar fractures. A preliminary report. $J$ Bone Joint Surg Am 75: 162-167.

9. Denis $F(1983)$ The three column spine and its significance in the classification of acute thoracolumbar spinal injuries. Spine (Phila Pa 1976) 8: 817-831.

10. Bergmark A (1989) Stability of the lumbar spine. A study in mechanical engineering. Acta Orthop Scand Suppl 230: 1-54

11. Biedermann $L$ (1994) Biomechanics of pedicle fixation as related to implant design. Presented at the American - European Meeting on Pedicle fixation of the Spine and Other Advanced Techniques. Munich, Germany.

12. Rohlmann A, Bergmann G, Graichen F, Weber U (2000) Changes in the loads on an internal spinal fixator after iliac-crest autograft. J Bone Joint Surg $\mathrm{Br} 82$ : 445-449.

13. Wang XY, Dai LY, Xu HZ, Chi YL (2007) The load-sharing classification of thoracolumbar fractures: an in vitro biomechanical validation. Spine (Phila Pa 1976) 32: 1214-1219. 
14. Dai LY, Jin WJ (2005) Interobserver and intraobserver reliability in the load sharing classification of the assessment of thoracolumbar burst fractures. Spine (Phila Pa 1976) 30: 354-358.

15. Elzinga M, Segers M, Siebenga J, Heilbron E, de Lange-de Klerk ES, et al. (2012) Inter- and intraobserver agreement on the Load Sharing Classification of thoracolumbar spine fractures. Injury 43: 416-422.

16. Parker JW, Lane JR, Karaikovic EE, Gaines RW (2000) Successful shortsegment instrumentation and fusion for thoracolumbar spine fractures: a consecutive 41/2-year series. Spine (Phila Pa 1976) 25: 1157-1170.

17. Aligizakis AC, Katonis PG, Sapkas G, Papagelopoulos PJ, Galanakis I, et al. (2003) Gertzbein and load sharing classifications for unstable thoracolumbar fractures. Clin Orthop Relat Res : 77-85

18. Dai LY, Jiang LS, Jiang SD (2009) Anterior-only stabilization using plating with bone structural autograft versus titanium mesh cages for two- or three-column thoracolumbar burst fractures: a prospective randomized study. Spine 34: 1429-1435.

19. Korovessis P, Baikousis A, Zacharatos S, Petsinis G, Koureas G, et al. (2006) Combined anterior plus posterior stabilization versus posterior short-segment instrumentation and fusion for mid-lumbar (L2-L4) burst fractures. Spine 31: 859-868.

20. Aligizakis A, Katonis P, Stergiopoulos K, Galanakis I, Karabekios S, et al. (2002) Functional outcome of burst fractures of the thoracolumbar spine managed non-operatively, with early ambulation, evaluated using the load sharing classification. Acta Orthop Belg 68: 279-287.

21. Dai LY, Jiang LS, Jiang SD (2008) Conservative treatment of thoracolumbar burst fractures: a long-term follow-up results with special reference to the load sharing classification. Spine (Phila Pa 1976) 33: 2536-2544.
22. Kim DH, Jahng TA, Balabhadra RS, Potulski M, Beisse R (2004) Thoracoscopic transdiaphragmatic approach to thoracolumbar junction fractures. Spine $\mathrm{J} 4$ 317-328.

23. Verlaan JJ, Diekerhof CH, Buskens E, van der Tweel I, Verbout AJ, et al. (2004) Surgical treatment of traumatic fractures of the thoracic and lumbar spine: a systematic review of the literature on techniques, complications, and outcome. Spine (Phila Pa 1976) 29: 803-814.

24. Wood KB, Bohn D, Mehbod A (2005) Anterior versus posterior treatment of stable thoracolumbar burst fractures without neurologic deficit: a prospective randomized study. J Spinal Disord Tech. 18 Suppl: S15-S23.

25. Ayberk G, Ozveren MF, Altundal N, Tosun H, Seckin Z, et al. (2008) Three column stabilization through posterior approach alone: transpedicular placement of distractable cage with transpedicular screw fixation. Neurol Med Chir (Tokyo) 48: 8-14.

26. Sasani M, Ozer AF (2009) Single-stage posterior corpectomy and expandable cage placement for treatment of thoracic or lumbar burst fractures. Spine (Phila Pa 1976) 34: E33-40.

27. Haiyun Y, Rui G, Shucai D, Zhanhua J, Xiaolin Z, et al. (2010) Three-column reconstruction through single posterior approach for the treatment of unstable thoracolumbar fracture. Spine (Phila Pa 1976) 35: E295-302.

28. Scholl BM, Theiss SM, Kirkpatrick JS (2006) Short segment fixation of thoracolumbar burst fractures. Orthopedics 29: 703-708.

29. Liu S, Li H, Liang C, Long H, Yu B, et al. (2009) Monosegmental transpedicula fixation for selected patients with thoracolumbar burst fractures. J Spinal Disord Tech 22: 38-44. 